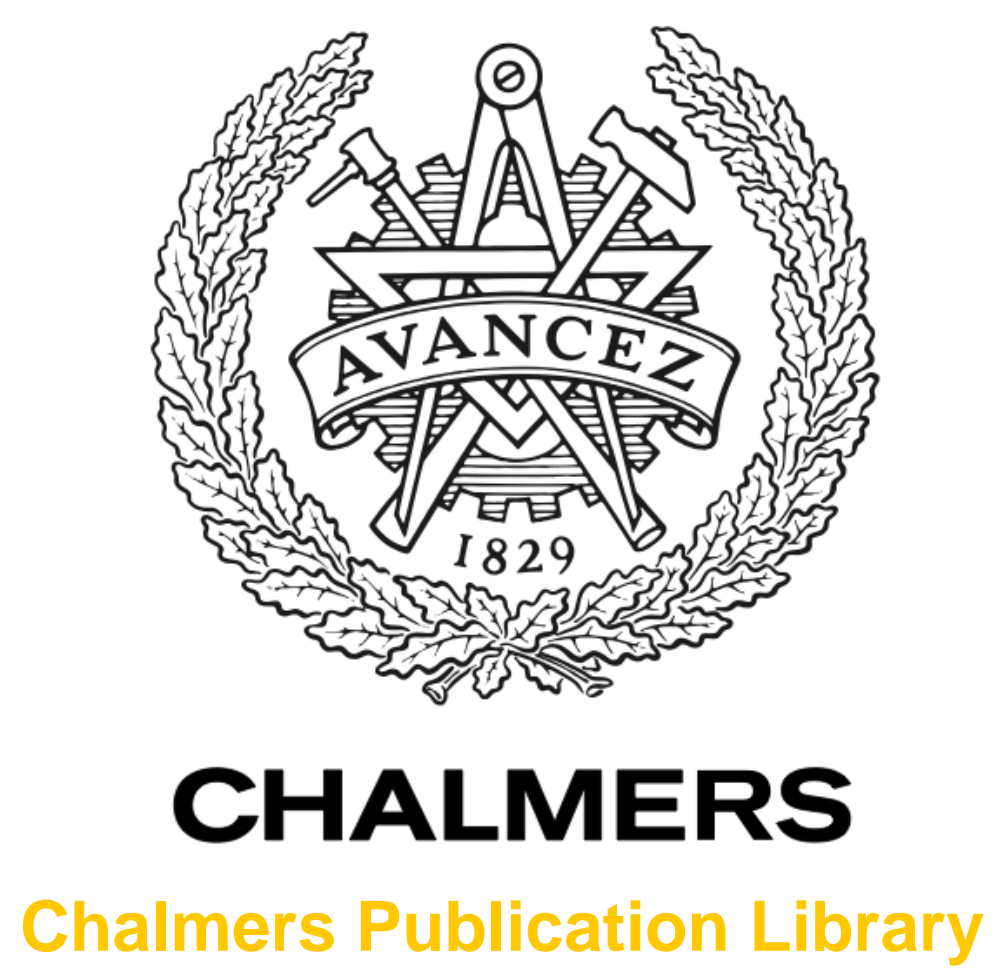

\title{
Social identity in construction: enactments and outcomes
}

This document has been downloaded from Chalmers Publication Library (CPL). It is the author's version of a work that was accepted for publication in:

\section{Construction Management and Economics (ISSN: 0144-6193)}

Citation for the published paper:

Löwstedt, M. ; Räisänen, C. (2014) "Social identity in construction: enactments and outcomes". Construction Management and Economics, vol. 32(11), pp. 1093-1105.

Downloaded from: http://publications.lib.chalmers.se/publication/204918

Notice: Changes introduced as a result of publishing processes such as copy-editing and formatting may not be reflected in this document. For a definitive version of this work, please refer to the published source. Please note that access to the published version might require a subscription. 


\author{
MARTIN LÖWSTEDT and CHRISTINE RÄISÄNEN \\ Department of Civil and Environmental Engineering, Construction \\ Management Division, Chalmers University of Technology, \\ Gothenburg, SE 41296 Sweden
}

To cite this work: Löwstedt, M. and Räisänen, C. (2014). Social identity in construction: enactments and outcomes. Construction Management and Economics, 32(11), 1093-1105.

\title{
Social identity in construction: Enactments and outcomes
}

\begin{abstract}
:
A social identity lens and theories of self-reinforcement are used to explore identity work and processes of identification at the micro-level in a large construction company. Rich data from a qualitative case study show that a strong collective identification is self-defining for the vast majority of managers in the organization, regardless of their role and function. This collective identification revolved around the trade "of being a construction worker", associated with the traits of being practically oriented and of having a long professional background in construction. This collective identification seems to self-reinforce itself by a combination of pulling and pushing movements and/or of "being blind" vis-à-vis those that stand outside its self-defining core, content, and behaviors. The results of the study suggest that self-defining at the individual and group levels has implications for organizational performance and outcomes. It is also suggested that the use of a social identity lens can help increase understanding of interpersonal relations, collaboration, and change initiatives in the construction industry.
\end{abstract}

Keywords: Collective identification, identity self-reinforcement, social identity. 


\section{INTRODUCTION}

The construction workforce has been characterized as having a positive self-image founded on a collective identification with the occupation of being a construction worker, i.e. the workers seem to identify more with the craft and trade of construction work rather than with a specific employee or job category (Applebaum, 1999). Other characteristics that have been highlighted are a shared sense of self-sufficiency and autonomy (Hayes, 2002, Applebaum, 1999), and a desire to do a "good job" (Styhre, 2011). Attention has also been directed toward the industry's masculine mind-set, often manifested in a proclivity toward rough, tough, and heavy physical work (e.g. Hayes, 2002; Ness, 2012; Applebaum, 1999; Greed, 2000, Dainty et al. 2000). For example, Ness (2012:662) argued that a typical construction worker associates masculinity with the nature of the occupation, "we perform dirty jobs because we are tough and masculine". Hayes (2002) pointed out that enduring "roughness" seems to be a component that stretches across all the different professions on construction sites. This proclivity toward hard work and doing a good job may also, as Thiel $(2007,2012)$ argues, be a manifestation of an adherence to class, i.e. of being (or having been) a manual worker with all its symbolic associations with hard manual labour. However, how identifications are (re)produced and maintained across a whole field and over time, and how they manifest at the individual, group and organizational levels remains under-researched in construction (Brown and Phua, 2011; Anvuur 2013; Phua 2013). If this gap is not filled, there is a risk that these identifications are reified and become stereotypes. 
Jenkins (2008:15) argued that "identity matters", but he also warned against casual reification. If identity is used to talk about everything, he states, "we end up talking about very little of any significance." Instead, he advocates unpacking identification processes and adopting a critical stance. In a similar vein, Coupland and Brown (2012: 2) proposed that identity per se needs to be de-emphasized, and attention should be paid to understanding the links obtaining between identity, organizational processes and specific outcomes. In other words, we should start viewing identity/ies as an ongoing dynamic process that unfolds (variously) in organizational practices. In construction, this would then represent the difference between merely acknowledging that the workforce of the industry seems to identify with a number of specific traits, to actually exploring how processes of identification are produced: how they unfold within a particular group and between groups, and how they relate to outcomes and to actual practices in the industry.

One of the most influential and prominent theoretical identity constructs is that of social identity (Ashforth and Mael, 1989; Haslam, 2004). Tajfel (1978:63) defined social identity as "that part of individuals' self-concept which derives from his [sic] knowledge of his membership of a social group (or groups) together with the value and emotional significance attached to that membership". In contrast to individual or personal identity, i.e. that which is unique to the individual and which distinguishes one individual from another, social identity is an overriding sense of shared traits by members of a group, which distinguishes between groups, and which serves as identification markers (e.g. Turner, Oakes, Haslam and McGarty, 
1994; Brewer and Gardner, 1996; Jenkins 2008). Social identity could therefore be viewed as a linking construct between the individual level, the group level and the organization level of analysis (e.g. Alvesson et al. 2008; Asforth et al. 2008; Ybema et al. 2009); however, to our knowledge social identity has yet to be applied in construction research.

Brown and Phua (2011) drew on similar arguments when they advocated a research agenda for social identity in construction. Drawing on scholars in organizational studies, they suggested that identities in the field of construction need to be explored as they unfold so as to capture their relations to "significant others" (pp. 91) on various levels. The transient, multi-organization, multistakeholder environment in which construction projects are delivered is seen as ideal for examining the processes and effects of identity plurality and possible synergies on performance (Phua, 2013). Because of its wide variety of involved professional fields, the industry is dependent on its workers' abilities to negotiate boundary interfaces, both intra and inter-organizationally (Dainty et al, 2006; Fellows and Liu 2012). In this respect, interpersonal relations, team spirit and collaboration are recurring challenges in construction management (Nicolini 2002). A social identity lens could be fruitful to explore cross-boundary interactions and negotiation to try and grasp the ongoing relations between personal identity (the self) and the collective social identifications at play. The purpose of this paper is to examine processes of identification in construction, focusing on the relational aspects between self and the social (collective and structure) in order to determine possible links between micro-level enactments 
and macro-level outcomes. From our analysis of rich empirical data from a qualitative case study, we perceived a marked sense of collective identification with "being a construction worker" among a cohort of managers from different functions and levels. We argue that this collective identification has implications for certain organizational outcomes, particularly in its manifestation in relation to "significant others". We avail ourselves of theories of organizational self-reinforcement in an attempt to understand and explain how this identification process can be sustained across organizational boundaries and levels, and suggest some possible implications.

We start the article by orienting the reader regarding the two theoretical frames used: social identity theories and self-reinforcing mechanisms. We then describe our overriding methodology. For the coherence of our story line, we separately describe the analysis of the two data sub-sets used and the respective findings: an interview study and an observation study. This is followed by a general discussion of the findings from both studies. We conclude the paper by highlighting the theoretical and practical implications of our findings for the organization and industry.

\section{THEORETICAL FRAMES}

\section{Social identity and identification in an organizational context}

A constructivist ontology predicates individuals as active agents in the development of their identities: identity work is a discursive, dynamic, iterative and relational process 
imbued with emotional tension and contestation (e.g. Alvesson and Wilmott 2002; Ashmore et al, 2004; Jenkins 2008; Ybema et al 2009). Alvesson and Willmott (2002) argued that subjectively construed work identities are available to the individuals as reflexively organized narratives derived from participation in competing discourses, and which afford a sense of existential continuity and security. Such narratives provide answers to questions like "who am I?" and "who do I want to become?" both for the self and for significant others with whom identity narratives are negotiated (Brown and Phua, 2011:84). Identity does not only involve verbal processes; it also involves the “ongoing cyclic interaction between narration and action" (Ezzy, 1998, p.251). Identity therefore refers to the subjective meanings and experiences addressed by the twin questions, "Who am I?" and - by implication - "How should I act?" (Cerulo, 1997). Jenkins (2008: 9) argued, however, that identity does not, and cannot, make people do anything; it is rather people who do identity for their own reasons and purposes. So, instead of 'identity', Jenkins maintains, we should only talk about ongoing and openended processes of 'identification'. Following Jenkins' advice we henceforth mostly use the term identification.

Ashforth et al. (2008: 334) argued that identification is closely related to identity. Identification, "is the process by which people come to define themselves, communicate that definition to others, and use that definition to navigate their lives, work-wise or other." Identification can be viewed as the process of identify as it unfolds; it takes place when an individual views a collective's defining essence as self-defining (Ashforth et al 2008: 329), and it has been referred to as the "perception of oneness or belongingness to some human aggregate" (Ashford and Mael, 1989: 21). For example "when a person's self-concept contains the same attributes as those in the perceived organizational 
identity" (Dutton et al., 1994:239). While "organizational identity" has traditionally been treated as the main object of identification, a number of recent developments have challenged such assumptions (Alvesson et al, 2008). Several authors, who study multiple targets of identification, acknowledge that "organization", as a formal, abstract identity, may not be the only interesting object or signifier of affiliation; factory, governance board, subsidiary, profession, product group, division, occupation, or gender and/or race subcultures, to name a few, may instead or simultaneously serve as sources of identification (Alvesson et al. 2008).

Ashforth et al (2008) portray identification as encompassing three dimensions: core, content and behaviour. The first pertains to cognition and affect relative the collective (who are we and how do we feel about issues and people). The second has to do with the collective's defining beliefs, values, norms and routines in a situated context. The third is related to what the collective does and says relative to outsiders. Tajfel and Turner (1986) argued that social identities are both "relational and comparative" as group members gain both a descriptive sense of their identity (who are we?) and an evaluative sense (how good are we?) by contrasting the in-group with an out-group(s). Pratt (1998) argued that identification is either self-referential (i.e., where an individual recognizes a collective or role deemed similar to that individual's self) or self-defining (i.e., where an individual changes to become more similar to the collective or role). Identity work entails the articulation of personal identities related to social and collective identification and, according to Ybema et al (2009: 300) "is a fundamental bridging concept between the individual and society." This "permanent dialectic" between the self (the agent) and the social (collective and structure) is what we have 
attempted to grasp in our study. How does this dialectic unfold and by what mechanisms is a social identification reinforced?

\section{Self-reinforcing mechanisms in organizations: becoming to remain the same?}

A 'self-reinforcing mechanism' is a social mechanism deployed within an organizational context, constituting a pattern of social practices, which, at least potentially, leads to an organizational lock-in (Sydow et al, 2009: 704). It can be understood as a corridor of limited scope of actions, and can be used to explain the dynamics of rigidification of an organizational pattern (Schreyögg and Sydow, 2011). A self-reinforcing mechanism can be viewed as an on-going process that aligns with an ontology of constant 'organizational becoming' (Tsoukas and Chia, 2002); but rather than being in a state of constant becoming to become something else, a self-reinforcing mechanism incrementally strengthens a becoming to remain the same. Schreyögg and Sydow (2011) argued that the idea of self-reinforcing mechanisms fits well with current interests in organizational practices and routines, rules and resources, contracts and cognitions, dynamics and change, and, in this paper, with an interest in identification.

Sydow et al. (2009) argued that it is often a combination of several self-reinforcing mechanisms that sustain a pattern in an organization. One of them is Adaptive Expectation Effects, which is based on the argument that an individual's preferences are expected to vary in response to the expectations of others. The dynamic of this selfreinforcing mechanism is driven by a self-fulfilling prophecy, in which organizational members are willing to adopt a certain behaviour because they expect others to do the same (Sydow et al. 2009). In the context of organizations, the informal diffusion of 
certain practices often follows this logic (Szulanski, 1996). Other drivers, such as legitimacy seeking and signalling then further reinforce the initial tendency. Those members who do not subscribe to the emerging mainstream behaviour may risk losing legitimacy and be stigmatized as outsiders, which further reinforces adherence to the prescribed behaviour (Sydow et al. 2009:700). In a similar way, identity formations are socially negotiated between the self and social prescriptions, where the presentation of self and the labelling of others play important roles, as our data shows.

Rhodes (2000) argued that organizational self-reinforcement is rather driven by a mobilization by the dominant group, which imposes its monologic and unitary perceptions of truth on those individuals that stand outside of it. In this respect, the reinforcing mechanisms can be metaphorically viewed as a combination of "centripetal" and "centrifugal" forces, alternately pulling organizational members towards established practice and/or pushing those that do not adhere away to the margins. In this respect, we can mention struggles between coercive governing identity meta-narratives authored by managers to maintain control and alternative meta-narratives in which workers re-author their selves to maintain their integrity (e.g. Clarke et al., 2009).

Similarly, Geiger and Antonacopoulou (2009) showed how dominant organizational narratives may sediment a self-sustaining frame, a "blind spot", which prevents organizational members from questioning its underlying principles. Blind spots, hence, are a strong driver of inertia. A dominant organizational narrative becomes selfreinforcing and exerts governance through ignoring and blocking alternative narratives (often informal narrative), and consequently tends to remain largely the same over time (e.g. Löwstedt and Räisänen 2012). Compared to the adaptive expectation effects 
described above, this self-reinforcement is not sustained by pulling or pushing forces actively exerted in relation to "what is outside", but rather by an inner centripetal force that eventually results in purposeful "blindness" (Geiger and Antonacopoulou, 2009).

Common for organizational self-reinforcing mechanisms seems to be that they are sustained via different combinations and re-combinations of pulling and pushing forces exerted in relation to those members that stand outside of the particular phenomenon which is being reinforced: the "outsiders" are pulled toward, pushed away, or merely ignored. Self-reinforcing mechanisms, just like social identity, thus, have strong relational aspects. The very essence of the sustaining feature is embedded in the interplay between the individual, the group, and the organization.

\section{THE CASE AND RESEARCH APPROACH IN BRIEF}

The data are drawn from a qualitative in-depth case study carried out in a large Swedish, globally distributed construction company, here referred to as Alpha. The case study covers Alpha's Swedish-based organization, which in 2012 employed over 10000 people, and had an aggregated turnover of approx. 30 billion SEK $(\sim 4,5$ billion USD). The company consists of a line organization and a number of central units (e.g. HR, purchasing, marketing, executive strategy group). The line is structured as a matrix, consisting of both geographical and functional units (e.g. housing, asphalt and concrete, infrastructure). The managerial levels in the lineorganization are: CEO and vice-CEO's, regional managers, district managers, project managers and site managers, most of whom started their careers working on site. 
The overall purpose of the case study was to examine change over time and its implications for strategy management. An explorative case study design was therefore chosen since the aim was to increase understanding of the unfolding of complex phenomena at the organizational micro level in situated contexts (Eisenhardt 1989; Alvesson and Sköldberg 2009; Yin 2010). Multiple qualitative methods, such as interviews, document analysis and field observations were used to mitigate researcher bias and enable triangulation and reflexivity (e.g. Dainty et al. 2006). We chose life stories and observations in order to shed light on the complexity of attitudes, beliefs and assumptions that pervade situated organizational contexts, and how these may influence individual and collective action (e.g. Räisänen and Gunnarson 2004).

Here we draw on two sub-sets of the data: 1) interviews in the form of life stories with 27 Alpha managers carried out in 2010, in which they gave an account of their work trajectory in the industry and at Alpha, and 2) observations of three away-day strategy workshops carried out during 2010 and 2011 with Alpha top, middle and project managers. The two data sets build on each other and demonstrate the explorative and incremental nature of this study, in which exploration entails an iterative process alternating between enquiry of the theory and scrutiny of the empirical data (e.g. Eisenhardt 1989; Langley 1999).

While the initial purpose of the interviews had been to explore organizational change, an interesting phenomenon emerged from the data. In their life stories, the majority of the managers, independent of organisational level, articulated a strong sense of collective identification in relation to "who we are" and "what we do" at Alpha. This salient voicing of communality impelled us to re-analyze the data, this time applying an identity lens, 
which resulted in a pinpointing of three dimensions of identity manifestation: a collective core, content, and behaviour (Ashforth et al. 2008). Since the stories were retrospective, the next step was to study the ways in which identities unfold in interaction with others in a situated context; hence the observation study.

In the following, we deal with the sub-sets of data separately. Besides representing interview-data and observation-data respectively, the two subsets also represent how a collective construction of identification is manifested in relation to two different categories of outsiders that we call: "outsiders-within" and "outsiders" (inspired by Tajfel and Turner's (1986) notion of in-group and out-group). Contrary to the traditional academic article format, we have chosen to conflate method/procedure descriptions with analysis of the data for each data-set since we believe that this structure better represents the story line of the research process.

\section{Sub-set 1. Collective identification through personal retrospection: tensions between in-group and "outsiders-within"}

The 27 interviewees represented a wide range of manager positions and functions: district and regional managers sampled from most of the functional and geographical units as well as managers from central units, including HR, purchasing, competence and strategy development, marketing, control and processes. During the interviews that lasted between 1-2 hours, the respondents were asked to describe their professional background, and then prompted to give a retrospective account of organizational changes during their time at Alpha. They were encouraged to "tell their own stories" of 
organizational events, according to their own perceived time lines (Cladinin and Conelley, 2000; Gill, 2001).

All the interviews were recorded and transcribed verbatim. A narrative analysis was then applied on the data, which means that the various accounts or fragments of accounts of organizational practices and events were coded, and plots linking the sequence fragments were identified (Czarniawska, 2004) The analysis was conducted by both authors, and resulted in fairly similar interpretations. The differences were then resolved through common engagement with the data and in dialogue.

The analysis revealed strong communalities in the managers' narratives of how "change at Alpha happens" over time. More interestingly, it highlighted a common or dominant meta-narrative of how organizing happens at Alpha (for further details concerning this particular study, see Löwstedt and Räisänen, 2012). The distinguishing feature of this narrative was that it seemed to be underpinned by a reactive behaviour; the modus operandi being to "extinguish fires" as these were ignited rather than to work proactively at trying to prevent them. One of the interviewees used an interesting sport metaphor to describe Alpha's mindset:

“Alpha plays ... if you think of table tennis ... then we play back-spin balls, we play defensively..."1

\footnotetext{
${ }^{1}$ NOTE: the data quotes and accounts in this paper have been translated from Swedish by a native speaker of both English and Swedish
} 
What was striking was that among the 27 narratives collected, there were only three that contradicted this meta-narrative. Interestingly, the three managers with alternative narratives had been at Alpha a far shorter time than the rest of the respondents, and their professional backgrounds differed from those of the others. In these alternative narratives, the respondents' identification relative to Alpha was one of frustration, criticism and distancing. The tensions we perceived between the dominant narrative and the alternative narratives, therefore prompted a re-analysis of the data, this time focusing on the identity talk, i.e. how the interviewees' identities and identification were articulated in the narratives, how they subjectively positioned themselves vis-à-vis each other and vis-à-vis Alpha.

This re-analysis revealed a collective identification that was closely associated with notions of the craftsmanship that "being a construction worker" embodied. Whereas this formulation is ours, it encapsulates the many different individual formulations of the strong sense of collective identification with the craft and trade of construction work carried out on building sites. Even though the interviewees were managers, they articulated similar graphic associations with their ties to the building site rather than with the strategic duties and responsibilities of management. For example, they repeatedly foregrounded the operative level and activities (i.e. production), verbalising a marked practical and problem-solving orientation; they expressed pride in the craftsmanship of the profession; and, they used hyperbolic references to their (own) formative grounding in the projects on sites. The dominant narrative was largely devoid of visionary or long-term views or plans, and although there were frequent statements showing their awareness of this lack (e.g. "we play back-spin balls"), these remained statements of "fact" rather than self-criticism. 
This commonality of identification suggests that there was indeed a strong collective social identity in the organization. In other words, there was a common representation of "who we are", and of "what we do" re-produced in the dominant narrative, which simultaneously reinforced the identification of a salient in-group (e.g. Ashmore et al, 2004; Jenkins, 2008; Ashforth et al, 2008)

What the dominant identity meta-narrative depicts is an organization where employees have a common construction history, and have earned legitimacy by starting their careers on the building site and then climbing the hierarchical ladder up through the ranks to become higher-level managers. This common path was manifest in the respondents' strong affinity and affect toward the operative side of the organization, the projects, despite their line allegiance and responsibilities. This strong collective identification with the projects and building sites seemed to define their identities within the organisation and the in-group status.

The minority group of colleagues we call "outsiders-within" were not steeped in the same mould as the in-group members in that they did not have the preferred construction background or the proclivities expressed in the dominant narrative. They had no experience of working in construction projects or on building sites. All of them were graduates of Business Schools and had been recruited straight into strategyrelated positions in the central organizational units rather than to the projects. What differentiated these managers' narratives was an articulated criticism of the reactive mentality of the in-group: 
“Yeah, you know, our organizational development is reactive and driven by adaptations. We adapt to the market .... for example: Oh! did the materials cost increase! ... Let's do something about that! [ironic tone]... or: Oh! the subsidies have been withdrawn! So, let's do something! [ironic tone]. It is, you know, in some way a reactive move. Instead of wanting something, choosing the direction, and then sticking to that direction"

The outsiders-within were acutely aware that in the eyes of the in-group they fell short of the ideal image of a "construction worker", an image which, over time, has been etched into the fabric of the organisation. The outsider-within quoted here had been headhunted from outside the construction sphere to a strategic executive position. He further describes his effort of identification:

"After 1,5 years [in the organisation] I realized that I did not know² construction, so instead I concentrated on the things that I do know. I mean $90 \%$ of the managers in this company know construction so bloody well! So why do I have to know it too? I mean, instead they should learn more of what I know than the other way around [...] But, they want me to learn production, they want to cast me in the same mould because they believe that is the key to success, that I know as much about production as possible"

In this narrative, we can feel the exasperation of the speaker, the "I", who does not fit the collective "we" identification of "what Alpha is" and "what Alpha does". He tried for 1,5 years to identify, but came to realise that it was a futile endeavour. It is interesting to note that in the previous quote, the same individual sees himself as a part of the organization, "our", but simultaneously, as reflected in the ironic tone, distances himself

\footnotetext{
${ }^{2}$ NOTE: the underscoring represents speaker emphasis
} 
from the in-group's collective identification. The quote above also demonstrates how closely identification is linked to affect. As his narrative progresses, the speaker becomes increasingly emotional:

"And it is not so bloody easy! What can I say! It is hard to ... I don't have credibility [...] and they pay me less because I don't know construction. But they should pay me more because I have other knowledge."

Another of the outsiders-within summarised how the in-group marks its boundary to the outsiders-within:

"I have so many times been told that to get somewhere [in Alpha] I would need to go out and work on the construction sites for a time"

This manager had also recently been recruited from outside the construction sphere to a strategic position. Even though the prerequisites for the position were strategic capabilities rather than construction skills, this manager was tacitly marginalised. In the data there are several examples of how colleagues marginalise colleagues due to the latters' lack of identification with the preferred characteristics of the in-group.

The sense of a collective identification found in the interview study evoked our curiosity. We therefore decided to study how this collective identification manifested itself in situ, in an encounter with another category of "outsiders". The next section presents the results from an observation study where we explored the tensions between managers in Alpha and a group of external consultants. 


\section{Sub-set 2. Collective identification as it unfolds: tensions between in-group and “outsiders"}

The context: In the beginning of the 2010s, Alpha re-formulated their strategic direction to focus on extending the business volume. The communication and consolidation of the new strategy in the organisation's business plans for 2012-2015 was to be executed by consultant-led strategy workshops for various managerial levels. In 2011 external consultants were hired to organize and run mandatory three-day strategy workshops (aka away days) at a designated conference facility.

We sat in as observers during three full workshop sets (nine days in total). The three workshop sets were selected to represent a varied sample of top-level and middle-range managers from different functions and geographical districts. The observations comprised all the workshop activities e.g. consultants' lectures, discussions, participant presentations, individual and group exercises. We sat outside the circle of workshop participants and did not engage in any of the formal workshop activities. We felt that the participants as well as the consultants seemed to forget our presence in the room quite fast. Moreover, we also observed the informal interactions by joining the workshop participants for breakfasts, lunches, dinners, breaks and after-work mingling.

An important part of participant observation is to search for patterns (Angrosino, 2007). Here we focused specifically on patterns of the processes of identification that unfolded in the encounters between Alpha's managers and the consultants. As observers of these 
encounters we could notice phenomena, attitudinal manifestations and particular behaviours, which seemed to be sedimented in the different cultures and therefore remained hidden, rendering the actors blind and deaf to their own actions and talk (Merriam, 1988). As Czarniawska (2007: 21) puts it: “ An observer can never know better than an actor; a stranger cannot say more about any culture than a native, but observers and strangers can see different things than actors and natives can". Over 100 pages of field notes were taken to document formal and informal activities in these workshops. These field notes were then compared and synthesized, read and re-read

In the following, we highlight episodes from the strategy workshop that show how an ingroup, the managers, invoked and reinforced a collective identity to resist novel ideas introduced by a group of outsiders. The empirical examples are sorted into two parts: the interactions between top-managers and consultants; and the interactions between a middle-management range (line middle managers of geographically distributed districts, functional and support middle managers and project managers) and consultants. Site managers were not invited to attend the workshops. In the following we have aggregated the data. These examples provide a deeper understanding of how identification mechanisms are mobilised in practice, and how they, on the one hand lead to self-reinforcement of the dominant identification, and, on the other may block possible developments of new perspective and innovative ideas.

\section{Episodes from the top-managers workshop}

The first episode occurred at the beginning of the first day of the three-day workshop.

The consultants' agenda was to introduce a (new) analytical model for strategy work. The model was a well-known theoretical model in the strategy literature. After the 
preamble of presentations, one of the consultants started introducing the theory underpinning the chosen model. He was abruptly interrupted in mid sentence by one of the top-managers, who demanded to know what the intended use of this particular model was. The consultant answered that he would get to that later on; now he wanted to explain the theoretical underpinnings. This answer gave rise to displeased whispers among the participants, followed by the question:

Top Manager (TM): "You said earlier that you have no prior experience of working with construction companies... [Pause, silence in the room]... so, if you were to describe Alpha in four words, which ones would you choose?

The consultants looked somewhat puzzled, and refrained from responding. The manager then continued:

TM: "We are a bit special you know"

In this short exchange, the managers articulate collective identification in "we", which not only distances them as a group from the consultant group, but their claim also positions them as "special" in contrast to the consultants who are "not special". By extension, we can interpret the claim as meaning that the consultants are positioned as outsiders, rendering their models irrelevant to the in-group.

Over and over again the participants interrupted the consultants in their attempts to elaborate on the model. The managers' criticisms were directed at the abstract and 
theoretical nature of the model, i.e. its apparent lack of alignment with "their" practice. The managers voiced their dissatisfaction in strong directives:

TM: You should "Alphafy" this [the model]! ...these slides should be related to practical examples in Alpha!

A collective identification in relation to the consultants is also manifest in a concerted, and seemingly staged, misunderstanding of what the consultants were trying to convey. This misunderstanding was exacerbated by the apparent unwillingness of the managers to listen (interruptions and disruptive undertone comments) to what the consultants said, which they in turn legitimised through their apparent lack of understanding. Thus, they positioned the consultants as carrying the whole explanatory burden, and concluding that these were unable to fulfil it.

Another token of collective identification is manifest in the next quote:

TM: It is hard to understand this model [short emphatic pause] and if we don't understand it then the middle managers won't either.

Another illustrative example is the following loaded exchange:

TM: You can't have this type of assignments.

Consultant: What do you mean ... why not? 
TM: They [middle-range managers] will not understand them."

Simultaneously, the top manager in question also voiced his identification with the middle-level managers in that he too does not understand:

Consultant: It [the model] is easy to use but harder to apply and adapt.

TM: Excuse me! [rudely interrupting] Did you say it was easy to use! Now you frighten me!

Another contentious issue is that of language. The consultants' models, and most of their slides, are in English, in line with common practice in business-school consultancy. This practice could also be expected in a global firm, even though the workshops only involved the Swedish organisation. However, the use of English gave rise to a range of complaints.

TM: Will this be in English? (Referring to text in English)

Consultant: That's how we planned it, yes.

TM: You should not have it in English! You should translate it to Swedish for them!

The statement ends there, and it is not clear if the top-management group themselves wanted the assignment translated to Swedish or not. An example further on shows that the top-manager's advice was valid since the use of English was an iterated aggravation in most of the workshops down the line, including those we observed. 
Over the course of the three days, the already tense atmosphere became more and more so. The consultants tried to control their frustration and their apparent surprise at the reactions of the top-managers. In a short exchange with them at the end of the workshop, one of them commented to us:

Consultant: We have been doing these workshops with so many different companies and we have never had any problems with the English.

As we have seen in an earlier statement, early on during the first day of this workshop, the managers indicated to the consultants (the outsiders) that "they were special". In their comments to us the consultants themselves indicated that Alpha's managers actually were "special" compared to the many companies they had worked with before; however, the connotation of the qualifier "special" was very different when ascribed the in-group by the outsider consultants.

We conclude this part with a statement by a top manager describing what identifies an Alpha worker:

TM: Yeah, you know ... there are many "doers" sitting here ... for us what counts is a bang and we cut to the chase.

Interestingly the manager uses the English word "doer" rather than the Swedish equivalent. The label of "doer" echoes through all the data, and could be said to epitomize the collective identification of Alpha's organizational members. 


\section{Episodes from the middle-range managers' workshop}

In the two observed middle-manager workshops, we perceived much of the same discursive tensions as in the top-management one: the controversies were the same, namely problems with the proposed model and manifestations of a low patience threshold among the participants, albeit these were less belligerently expressed. Here we show some examples.

The first extract is taken from early the first day. A consultant is in the middle of presenting the (same) model when one of the managers interrupts:

Middle-manager (MM): Hold on! Why do you have to use all these English terms?

This quote corroborates the top-manager's warning to the consultants earlier on, and also highlights a common identification in the organisation expressed in resistance to foreignness. The next examples are extracted from an episode when the consultants asked the participants to discuss each of five strategic bullet points in Alpha's new business plan. Instead of actually discussing the points, the participants started to elaborate on their self-identification as Alpha workers in an attempt to explain their lack of engagement in the workshop tasks so far:

MM: We are very focused on production ... we seldom sit down and reflect ... we are doers you know.

A comment from another manager shortly after this: 
MM: You know, we are the same type of personalities all of us ... on a "Myles-test" all of us are the same ... so as soon as we find ourselves in a diversified group things get questioned"

What was interesting in this workshop was the way in which it echoed the one with toplevel managers, even down to the use of terms such as the English "doer". It also echoed the dominant narrative that was identified in the interviews, e.g. focused on production, seldom sit down and reflect, being all the same. In the exchanges between the in-group and the outsiders, the characteristics of the dominant narrative are further reinforced through their discourse and behaviours, and are used to legitimise their lack of interest and refusal to take on new perspectives that come from these outsiders.

During the workshops the managers often sat in small groups, carrying out assigned tasks. While one of us was observing one of the groups, a discussion concerning the difficulty of finding good recruits to the purchasing and sales units occurred. Here the researcher was unable to keep quiet:

MM: It is very hard to find a good construction worker and then teach him [sic] how to deal with numbers?

Researcher: Why don't you find someone that already knows numbers and instead teach them about construction?

MM: That possibility never occurred to me! 
Here the researcher challenged the middle manager's beliefs and assumptions of what a "good manager" was. During the last days of the workshops this same manager presented this as a "new idea" for recruitment practice to the rest of the group. This incident epitomises the strongly ingrained and somewhat blind collective identification that exist in the in-group regarding "what or how to be" in a construction organisation.

\section{DISCUSSION}

Based on rich data from an on-going case study over time, we have identified instances of collective organizational identification at several managerial levels in a large construction company. This collective identification revolved around a dominant and regulating discourse which reflected the three main dimensions of identification (Ashforth et al 2008): its core reflected in references to "who we are and what we feel about issues and people"; its content reflected in references to "what our values, norms and routines are", and behaviours reflected in reference to "what the collective does and says relative to outsiders".

The core of the collective identification found was articulated in frequent positive allusions to experiences of working on sites and "being a doer". This core dimension is furthermore closely related to the content, the norms and social routines adopted by the collective in the organizational context. Here we found that a collective identification revolved around a certain career path in construction. Managers at all levels are seldom recruited from outside of construction spheres, but tend to be fostered in building and infrastructure projects, where they acquire their accreditation for promotion. Typically the vast majority of the managers in the data had climbed the hierarchical ladder in 
accordance with this established organizational norm. The managers further signalled a strong sense of identification with a practical orientation and a mentality of "doers" i.e. firefighters rather than "thinkers" i.e. firelighters (Barber and Warn, 2005), which was epitomized in the metaphor, "to play back-spin balls", and day-to-day problem solving (see also Löwstedt and Räisänen 2012).

This core and content in their identity discourse can be seen as the collective's defining essence by which the individual managers in this study self-defined themselves (Ashforth et al 2008: 329) through a perception of oneness and belongingness to a certain in-group (Ashford and Mael, 1989). This particular core and content was found in the self-defining of managers from wide-ranging parts of the organization, including three different hierarchal levels of the line organization (project managers, district managers, regional managers), representing several different geographical units from all over Sweden, as well as managers from a range of central units (e.g. HR, Marketing, Economy, Strategy and Development). The self-defining collective identification can therefore be seen as a permeating feature, bridging the individual, group, and organizational levels (e.g. Alvesson et al. 2008; Asforth et al. 2008; Ybema et al. 2009). The core and content of the collective identification, however, only really became clear for us via the third dimension, the behaviour, reflected in reference to what the collective does and says in relation to outsiders (Ashforth et al 2008); that is, by contrasting the ingroup with a salient out-group(s) (Tajfel and Turner, 1986), or as Brown and Phua (2011) put it: "how it [the in-group] manifests in relation to significant others" (pp.88).

In this paper, we have explored how the collective identification manifests itself by studying what the in-group do and say in relation to two categories of outsiders: 
"outsiders within" and "outsiders". These different encounters helped to elucidate the particular core and content defining the in-group. In the encounter with a group of consultants we saw how the managers collectively, across three hierarchical levels of the line organization, collectively identified themselves as "special" in relation to the group of consultants, emphasizing their more practical orientation, their "doing" mentality, and distancing themselves both in what they said and what they did in relation to the consultant's theoretically oriented agenda. The frustration voiced by the outsiderswithin corroborates the strength of the core and content as a defining essence of the salient in-group's collective identification, and supports the argument by Alvesson et al (2008) that "the organization" is not necessarily the only object of identification (even though it traditionally has been treated as such in the literature). It is not the organizational affiliation with "Alpha" that is the object of identification here, but the craftsmanship of "being a construction workers" which the respondents associated with even though they were managers. This centrifugal pull of a (maybe) idealised building site common to all the in-group participants of the two data-sets not only supports Hayes (2002) suggestion that identity spans several levels of on-site professions, but also permeates managerial levels. The building site could be said to form a symbolic icon of organisational memory. The encounter with the "outsiders-within" further illustrates this. Those few managers that work for Alpha but who lacked a long background on the production side of construction, complained of being exposed to signalling from the ingroup that they needed to acquire the proper content and "go out and learn construction in order to get somewhere in Alpha" (similar tensions are described in Raja et al (2012) between HR professionals, i.e. "outsiders within" according to our definition and insider operations managers). 
We see organizational identification as a process in which a collective identification over time, triggered by diverse contingencies, has been established. While we believe that processes of identification are ongoing (Jenkins, 2008) the results reported in this study suggest that the self-defining discourse of the collective identification through its multiple iterations becomes an on-going self-reinforcing mechanism (Sydow et al. 2009) through its ability to pull in, push away and be blind to the alternative identities of outsiders.

In the results, we showed how these forces manifest in the interplay of insiders with two categories of outsiders: the "outsiders" i.e. consultants whose job it was to introduce a new organizational practice and the "outsiders within" i.e. managers that are employed by Alpha, but whose background differs from the norm. The data from the observation study show how Alpha managers signal an immediate collective distancing from the consultants by questioning their agenda and positioning themselves as "a bit special". This distance was maintained, and escalated, throughout the workshop by as we see it, pulling and pushing forces in collision (Sydow et al. 2009). On one side the consultants were invited to "Alphafy" their message, but when the consultants resisted the invitation, their discourse and enactments were stigmatized as not valuable and not doable for the in-group. This pull-push movement could also be understood as rhetorical performance to undermine the outsiders while underpinning Alpha's uniqueness, in other word a motivation for being blind (Geiger and Antonacopoulou, 2009).

The accounts of the "outsiders-within" show similar aspects of signalling of collective identification in their being subjected to both pulling and pushing forces. There is, on the one hand, a strong pulling force urging them to become more like the collective in-group. 
This pulling force offers a path that if taken will lead to organizational legitimacy: "go out and work in the construction projects if you want to get somewhere in Alpha". These strong pulling forces could be seen as unitary monologic truth (Rhodes, 2000) imposed on "outsiders within" (that would in turn reinforce the legitimacy of the in-group). There are also strong forces pushing outsiders within away from identification with the organization through stigmatizing them as not really belonging (Sydow et al. 2009). This latter force is also a manifestation of blindness on the part of Alpha, which on the one hand recruits outside competence because it needs it, but at the same time refuses to see the actual and potential resources that the competence contribute (Geiger and Antonacopoulou, 2009).

\section{CONCLUSIONS AND IMPLICATIONS}

This paper has focused on social identity in construction. More specifically it has shown how a particular collective identification is self-defining for the vast majority of managers in the construction company studied, regardless of their different roles, functions or responsibilities. Drawing on theories of self-reinforcing mechanisms, we showed how collective identification endures over time and across organizational boundaries through combined pulling and pushing forces underpinned by a blindness vis-à-vis "the other", i.e. what Geiger and Antonacopoulou (2009) characterized as a "blind spot". The in-group, as we have shown, resisted what it deemed as being outside its self-defining core, content, and behavior. We argue that the core, content, and behavior (Ashforth et al. 2008) of this collective identification by pervading the organizational culture also functions 
as a bridge between individual, group, and organizational level. The findings presented here suggest that the self-defining at the individual level and group level do implicate organizational performance and outcomes as a result of how it manifests itself in relation to two categories of others (Brown and Phua, 2011). In the encounter with the consultants (the outsiders), the collective identification of the managers negatively influenced the intended outcome of the strategyworkshop initiative by resisting that which they "did not already know". This furthermore implicates outcome on the organizational level, in that the strategy suggested by the consultants will hardly be embraced by Alpha.

The in-group's marginalization of the outsiders-within may also have both direct and indirect consequences for organizational outcomes. The collective identification, we argue, de-legitimizes colleagues with non-traditional (nonpreferred) professional backgrounds by stigmatizing this group. Such behavior creates barriers that prevent "new" and specialized competencies to be taken up in the organization, which then blocks possibilities for new perspectives and ideas. Such a social process may also have a major impact on the kind of competencies that the organization attract and manage to sustain and develop, which in turn implicates the competitive leverage.

While the findings here are based upon an in-depth case in a single organization, we argue that certain aspects of our findings indicate that a collective identification may be embedded at the industry level as well. As discussed above, it was not "Alpha" that was the "object" of identification (Alvesson et al, 2008), but the craftsmanship and trade of "being a construction worker". This seems to suggest 
that identification on the micro-level relates to the industry level insofar as the managers self-defining related to the industry-specific trade rather than to a certain organization or job category. Our speculation on this point seems to be supported by Applebaum's (1999) study of construction workers in the US, where he found a similar identification to the trade rather than to the job or organization.

It has been argued that construction is an industry based on a high heterogeneous composition of different professional groups and therefore particularly dependent on interpersonal relations and collaboration between these groups (Nicolini 2002; Dainty et al, 2006; Fellows and Liu 2012). In this respect a variety of "in-groups" and "out-groups", within and between which processes of identification unfold on a daily basis. While this paper has focused on two specific types of group encounters, we hope that our findings awaken further interest in using an identity lens to explore other types of group encounters. Aggregated insights from a larger variety of different encounters in the construction industry would not only give us deeper insights into identity production and reproduction of the workforce, but also increase our understanding of construction-specific practices by linking individual and group identity phenomena to outcomes, or, as in our case, to non-outcomes.

A well-rehearsed myth about the construction industry is that it is conservative and slow to change. This oft repeated notion is probably the origin of the "uniquely backward" label voiced in the research community, by politicians and policymakers (e.g Kadefors, 1995; Dubois and Gadde 2002; Hayes 2002; Winch 2003; Woudhuysen and Abley, 2004). The process of identification described in this paper relates to change in that its self-defining core seems to obstruct change by 
reinforcing itself to remain the same. We do not, however, suggest that this observation on our part should necessarily be interpreted as signaling a "backward" industry. As many researchers have argued, much of the construction's alleged "resistance to change" may in fact be a way of dealing with the chaotic, complex and constantly negotiated nature of construction projects (Higgin et al 1966; Dubois and Gadde 2002; Cicmil and Marhall 2005; Ness 2010). Having a strong grounded identity and collective ways of doing things may therefore be a valuable strength, rather than an unfortunate weakness when operating in the midst of the constant flux of the construction (site) environment. It would therefore be counterproductive to criticize Alpha's managers of "backwardness" because they resisted the management consultant's suggestions. Rather, they may have been resisting the consultants' taking for granted that the "new" abstract theories these wanted to impose would à priori fit the construction organization's context; in other words, they may have been resisting the consultants' lack of sensitivity or knowledge of the culture of the construction field (Räisänen and Löwstedt, 2014).

Regardless of which, the point here is not to discuss change in construction per se, but to refer to our findings to argue that identity can be linked to change. We need to remember that many of us that are concerned with change in construction are outsiders. Whether we are researchers, politicians, policy-makers or civil servants, we remain outsiders vis-á-vis a significant in-group. And whether we interact, prescribe or study, we can benefit from having Cerulo's (1997) thesis in mind: "Who we are" will affect "How we act". 


\section{REFERENCES}

Alvesson, M., Ashcraft, K. L. and Thomas, R. (2008) Identity matters:

Reflections on the construction of identity scholarship in organization studies. Organization, 15(1), 5-28.

Alvesson, M. and Sköldberg, K. (2009) Reflexive methodology: New vistas for qualitative research, Sage, London.

Alvesson, M. and Willmott, H. (2002) Identity regulation as organizational control: Producing the appropriate individual. Journal of management studies, 39(5), 619-644.

Angrosino, M. (2007) Doing ethnographic and observational research, Sage, London.

Anvuur, A. M. (2013). Effects of workgroup identification on cooperative behaviour in construction projects. Proceedings of HKU-HKHA International Conference 2013, May 2013, Hong Kong.

Applebaum, H. A. (1999). Construction workers, USA. Greenwood Publishing Group. 
Ashforth, B. E., Harrison, S. H., and Corley, K. G. (2008) Identification in organizations: An examination of four fundamental questions. Journal of Management, 34(3), 325-374.

Ashmore, R. D., Deaux, K. and McLaughlin-Volpe, T. (2004) An organizing framework for collective identity: Articulation and significance of multidimensionality. Psychological Bulletin, 130(1), 80-114.

Ashforth, B. E. and Mael, F. (1989) Social identity theory and the organization. Academy of management review, 14(1), 20-39.

Barber, E. and Warn, J. (2005) Leadership in projects: from firefighter to firelighter. Management Decisions, 43(7), 1032-1039.

Brewer, M. B. and Gardner, W. (1996) Who is this" We"? Levels of collective identity and self representations. Journal of personality and social psychology, 71(1), 83

Brown, A. D., and Phua, F. T. (2011) Subjectively construed identities and discourse: towards a research agenda for construction management. Construction Management and Economics, 29(1), 83-95.

Cerulo, K. A. (1997) Identity construction: New issues, new directions. Annual review of Sociology, 23, 385-409. 
Cicmil, S., and Marshall, D. (2005) Insights into collaboration at the project level: complexity, social interaction and procurement mechanisms. Building Research and Information, 33(6), 523-535.

Clandinin, D. J. and Connelly, F. M. (2000) Experience and story in qualitative research, Jossey-Bass, San Francisco.

Clarke, C. A., Brown, A. D. and Hailey, V. H. (2009).Working identities? Antagonistic discursive resources and managerial identity. Human Relations, 62(3), 323-352.

Coupland, C and Brown, A. D. (2012) Indentities in action: processes and outcomes. Scandinavian journal of Management, 28, 1-4.

Czarniawska, B. (2004) Narratives in Social Science Research, Thousand Oaks, CA.

Czarniawska-Joerges, B. (2007) Shadowing: and other techniques for doing fieldwork in modern societies, Copenhagen Business School Press, Copenhagen.

Dainty, A. R., Bagilhole, B. M., \& Neale, R. H. (2000) A grounded theory of women's career under-achievement in large UK construction companies. Construction Management \& Economics, 18(2), 239-250. 
Dainty, A., Moore, D. and Murray, M. (2006) Communication in construction: Theory and practice, Taylor \& Francis, Oxon.

Dubois, A., \& Gadde, L. E. (2002) The construction industry as a loosely coupled system: implications for productivity and innovation. Construction Management and Economics, 20(7), 621-631.

Dutton, J. E., Dukerich, J. M. and Harquail, C. V. (1994) Organizational images and member identification. Administrative science quarterly, 39(2), 239-263.

Eisenhardt, K. M. (1989) Building theories from case study research. Academy of management review, 14(4), 532-550.

Ezzy, D. (1998) Theorizing narrative identity. The Sociological Quarterly, 39(2), 239-252.

Fellows, R., and Liu, A. M. (2012) Managing organizational interfaces in engineering construction projects: addressing fragmentation and boundary issues across multiple interfaces. Construction Management and Economics, $30(8), 653-671$.

Geiger, D. and Antonacopoulou, E. (2009) Narratives and Organizational Dynamics Exploring Blind Spots and Organizational Inertia. The Journal of Applied Behavioral Science, 45(3), 411-436. 
Gill, P. B. (2001) Narrative inquiry: designing the processes, pathways and patterns of change. Systems Research and Behavioral Science, 18(4), 335-344.

Greed, C. (2000) Women in the construction professions: achieving critical mass. Gender, Work \& Organization, 7(3), 181-196.

Haslam, S. A. (2004) Psychology in organizations, Sage, London.

Hayes, N. (2002). Did manual workers want industrial welfare? Canteens, latrines and masculinity on British building sites 1918-1970. Journal of social history, 35(3), 637-658.

Higgin, G., Jessop, N., Bryant, D., Luckman, J., and Stringer, J. (1966) Interdependence and Uncertainty: A Study of the Building Industry. Tavistock publication: London.

Jenkins, R. (2008). Social identity. Routledge: Oxon.

Kadefors, A. (1995) Institutions in building projects: implications for flexibility and change. Scandinavian Journal of Management, 11(4), 395-408.

Langley, A. (1999) Strategies for theorizing from process data. Academy of Management Review, 24, 691-710. 
Löwstedt, M. and Räisänen, C. (2012) 'Playing back-spin balls': narrating organizational change in construction. Construction Management and Economics, 30(9), 795-806.

Merriam, S. B. (1988) Case study research in education: A qualitative approach, Jossey-Bass, San Fransisco.

Ness, K. (2010) Bringing order to chaos: the management of construction projects. In: 5th Making Projects Critical Workshop, 20-22 January 2010 Bristol Business School.

Ness, K. (2012) Constructing masculinity in the building trades: 'most jobs in the construction industry can be done by women'. Gender, Work \& Organization, 19(6), 654-676.

Nicolini, D. (2002) In search of "project chemistry", Construction Management and Economics, 20(2), 167-177.

Phua, F. T. (2013) Construction management research at the individual level of analysis: current status, gaps and future directions. Construction Management and Economics, 31(2), 167-179. 
Pratt, M.G. (1998) To be or not to be? Central questions in organizational identification. In Whetten, D.A. and Godfrey, P.C. (eds.) Identity in organizations: Building theory through conversations, 171-207, Sage, CA.

Raja, J., Green, S., Leiringer, R., Dainty, A. and Johnstone, S. (2013) Managing multiple forms of employment in the construction sector: implications for HRM. Human Resource Management Journal, 23(3), 313-328.

Rhodes, C. (2000) Doing knowledge at work, dialogue, monologue and power in organizational learning. In Garrick, J. and Rhodes, C. (eds.) Research and Knowledge at work, 217-231, Routledge, London.

Räisänen, C. and Gunnarsson, S. (2004) Multi-project organizations from a methodological perspective: challenges and rewards. In IRONOP VI conference proceedings. Turku: Åbo Akademi University Press.

Räisänen, C. and Löwstedt, M. (2014) Stakes and struggles in liminal spaces: construction practitioners interacting with management-consultants. Engineering Project Organization Journal, 4(2-3), 123-133.

Schreyögg, G. and Sydow, J. (2011) Organizational path dependence: A process view. Organization Studies, 32(3), 321-335. 
Styhre, A. (2011) In the circuit of credibility: construction workers and the norms of 'a good job'. Construction Management and Economics, 29(2), 199209.

Sydow, J., Schreyögg, G. and Koch, J. (2009) Organizational path dependence: Opening the black box. Academy of Management Review, 34(4), 689-709.

Szulanski, G. (1996) Exploring internal stickiness: Impediments to the transfer of best practice within the firm. Strategic management journal, 17, $27-43$

Tajfel, H. (1978) Social categorization, social identity and social comparison. In Tajfel, H. (eds.) Differentiation between social groups: Studies in the social psychology of intergroup relations, 61-76, Academic Press, London.

Tajfel, H. and Turner, J. C. (1986) The social identity theory of intergroup behavior. In Worchel, S. and Austin, W.G. (eds.) Psychology of intergroup relations, 7-24, Nelson-Hall, Chicago.

Thiel, D. (2007) Class in construction: London building workers, dirty work and physical cultures. The British journal of sociology, 58(2), 227-251.

Thiel, D. (2012) Builders: Class, Gender and Ethnicity in the Construction Industry. Routledge. 
Tsoukas, H. and Chia, R. (2002) On organizational becoming: Rethinking organizational change. Organization Science, 13(5), 567-582.

Turner, J. C., Oakes, P. J., Haslam, S. A. and McGarty, C. (1994) Self and collective: Cognition and social context. Personality and social psychology bulletin, 20, 454-454.

Winch, G. M. (2003) How innovative is construction? Comparing aggregated data on construction innovation and other sectors-a case of apples and pears. Construction Management and Economics, 21(6), 651-654.

Woudhuysen, J., and Abley, I. (2004). Why is construction so backward? Wiley Academy.

Ybema, S., Keenoy, T., Oswick, C., Beverungen, A., Ellis, N. and Sabelis, I. (2009) Articulating identities. Human Relations, 62(3), 299-322.

Yin, R. K. (2010). Qualitative research from start to finish. Guilford Press. 